http://jmscr.igmpublication.org/home/

ISSN (e)-2347-176x ISSN (p) 2455-0450

crossref DOI: https://dx.doi.org/10.18535/jmscr/v8i7.95

Journal Of Medical Science And Clinical Research

\title{
Parotid Cancers - A 5 Yr Experience at a Tertiary Care Centre
}

\author{
Authors \\ Dr Pandudasappa ${ }^{1}$, Dr Bhagavan. B.C ${ }^{2}$, Dr Deepak Lal .S. D ${ }^{3}$
}

${ }^{1}$ Associate Professor, Department of Surgical Oncology, Kempegowda Institute of Medical Sciences, Bengaluru, Karnataka, India

${ }^{2}$ Professor, Department of General Surgery, Kempegowda Institute of Medical Sciences, Bengaluru, Karnataka, India

${ }^{3}$ Junior Resident/ Post-graduate, Department of General Surgery, Kempegowda Institute of Medical Sciences, Bengaluru, Karnataka, India

\begin{abstract}
Background: From 1823 when the first documented parotidectomy was done, parotid tumors which form a majority of the salivary tumors with $70 \%$ being benign and have been studied ever since.

Aims and Objectives: To analyse parotid tumours at a tertiary care hospital and their diagnostic modalities, treatment and associated complications.

Methods: This prospective study was conducted on 68 patients who underwent parotidectomy from December 2014-Dcember 2019 for parotid tumours. Thorough clinical examination and facial nerve assessment done and subjected to radiological and pathological investigations.52 patients underwent superficial parotidectomy (46 patients for pleomorphic adenoma,6 patients for warthin tumour) and 14 patients underwent Total conservative parotidectomy (11 patients for parotid malignancy and 1 patients for pleomorphic adenoma recurrence and 1 patients pleomorphic adenoma involving deep lobe of parotid) and 1 underwent wide excision with neck dissection due to involvement of the hard palate post recurrence. Neck dissection also carried out in CT proven lymph node metastasis

Results: In our study, Usg with FNAC was found to have 90\% sensitivity, 98.3\% specificity, 90\% positive predictive value, a $90 \%$ negative predictive value and a $90 \%$ accuracy. Higher investigations such as CT scan was only advised for palpable neck nodes or in case of suspected metastasis 10 patients developed complication. Several complications have been reported in parotid surgery. Temporary facial nerve paresis was the most common postoperative complication. Most patient regained normal facial nerve function within 2 months from the onset.

Conclusion: The incidence of parotid tumors is seeing a shift towards the younger age group with clinical, radiological and pathological diagnosis being the best mode of approach. Parotidectomy is the currently the best treatment available with complications increasing in proportion to the extensiveness of the procedure with facial paresis being the most common.

Keywords: Parotid; parotidectomy; parotid tumor; facial nerve palsy.
\end{abstract}

\section{Introduction}

Salivary gland neoplasms are rare and constitute $3 \%$ to $4 \%$ of head and neck neoplasms. Most neoplasms arise in the parotid gland (70\%) and are more commonly seen in India compared to the western world with an incidence of about $3-10 \%$, presenting as neck swellings with multiple differentials such as Lipoma, Sebaceous cysts, lymphadenopathy, hematoma, mumps, parotitisetc $^{(1,2)}$

Ultrasound of the tumour presenting as swelling is the first investigation, yet not a confirmatory one, 
CT and MRI prove to be a burden to the patient in terms of cost and its lack of essentiality in all cases but defines the extent of the disease. FNAC provides a histological diagnosis but fails to define the extent. ${ }^{(3)}$

Reports in the literature have described the surgical technique and outcome achieved by parotidectomy ${ }^{(4)}$, however few reports have documented the complications of parotid gland surgery.This operation is associated with some typical complications owing to the unique surgical anatomy of the gland.Major complications include facial nerve paresis or paralysis, and minor complications include salivary fistula, auriculotemporal syndrome (gustatory sweating or Frey syndrome), great auricular nerve anesthesia, and hemorrhage, infection, seroma formation ${ }^{(7,8)}$

Facial palsy is the commonest post operative complication associated and hence the facial nerve tracing, identification, assessing its involvement and decision on its preservation plays a crucial role during the surgery for good post-operative results. ${ }^{(7,8)}$

Facial palsy longer than $24 \mathrm{~h}$ is not due to the local anaesthetics (if used). Temporary paresis causes include nerve division, stretch, compression, ligature entrapment, thermal and electrical injuries, and ischemia which can broadly be called operative trauma. When the surgeon is certain the nerve is preserved, the patient can be followed up for a period of 2 years to see for return of function, post which if paresis continues is considered as Permanent damage. ${ }^{(9,10)}$

This study is to understand the clinical, diagnostic and management modalities of the various parotid tumours faced in a tertiary care centre.

\section{Aim}

To analyse parotid tumours at a tertiary care hospital and their treatment and associated complications

\section{Materials and Methods}

This is a prospective study was conducted on 68 patients who underwent parotidectomy in the department of General Surgery and Oncosurgery of KIMS Hospital Bangalore from December 2014-December 2019 for parotid tumours.

Patients underwent careful history taking, complete clinical examination, and examination of facial nerve integrity before surgery.

Patients fulfilling one or more of the following criteria were excluded from the study: those with previous facial nerve palsy, neuromuscular diseases affecting the face, diabetic neuropathy, psychiatric disease, or any other condition that could influence the study or that might affect the completion of the study.

The patients were further subject to diagnostic tools to substantiate diagnosis such as-

1. Ultrasonography of the neck to know if the parotid swelling is solid or cystic, or to know the margins of the tumour, or to know the lobe that is involved.

2. Fine needle aspiration and cytology(FNAC)

3. CT scan of the head and neck if warranted Postparotidectomy facial nerve dysfunction was recorded using the House-Brackmann (H-B) grading scale, which ranges from I (normal) to VI (no movement). The degree of immediate facial nerve dysfunction was recorded.

These 68 patients with parotid swelling were subject to parotidectomy by modified blair incision and antegrade (65 patients) and retrograde approach (3 patients for anterior lying tumours) dissection is used for identifying the facial nerve and mobilization of parotid gland. After identifying facial nerve, electrocautery is avoided for haemostasis, and instead, ligatures and haemostatic clips are used which reduces the chances of nerve injury. A suction drain is left post extraction and haemostasis and suction drain is removed after $48-72 \mathrm{hrs}$ or if the output is less than $10 \mathrm{ml} /$ day.

For total conservative parotidectomy, once mobilization was completed, vascular slings are used to lift the nerve to prevent injury to nerve and continue dissection 


\section{JMSCR Vol||08||Issue||07||Page 579-585||July}

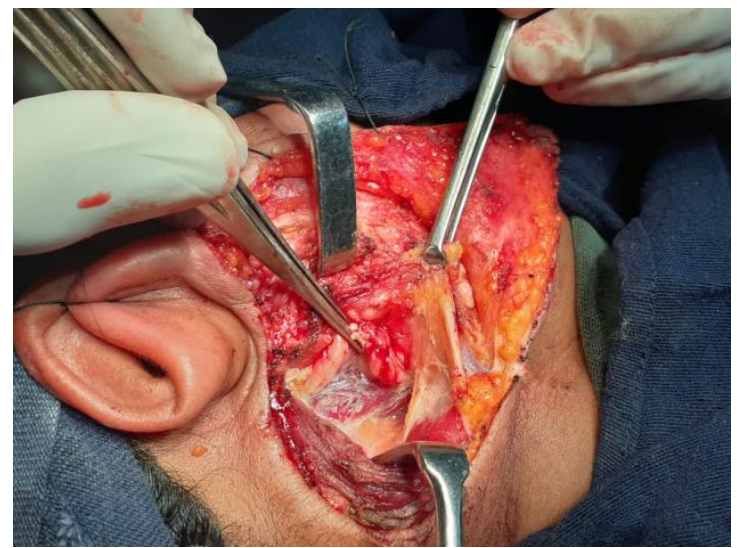

Figure 1 Superficial Parotidectomy

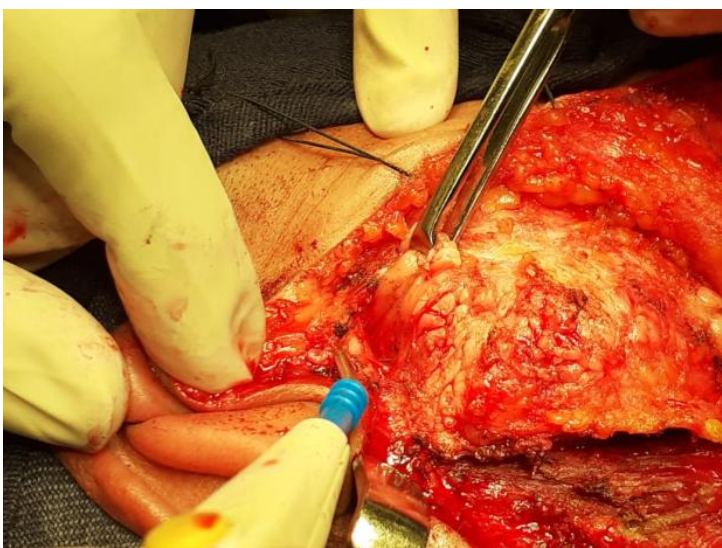

Figure 2 Total Parotidectomy

\section{Results}

\section{Age Distribution}

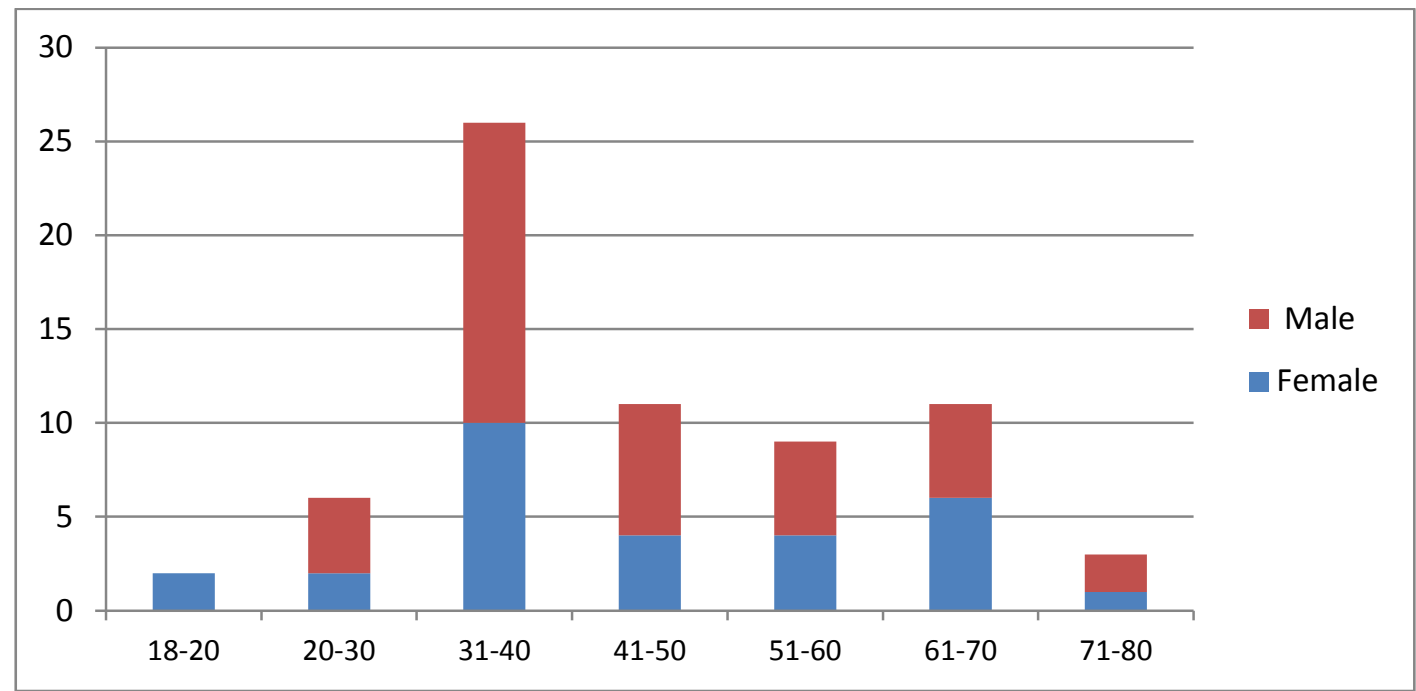

Chart No.-1 Age Distribution

The age of the patient with parotid tumours in the study group ranged from 18 to 80 years, with the mean age of 44 years. The maximum number of patients looming around the 31-40 years range.39 patients are male and 29 patients are female with male to female ratio of 1.34:1 Majority of these patients were from rural backgrounds $(63.3 \%)$ and give no significant family history or personal history with 1 recurrence post parotidectomy with palatal growth.

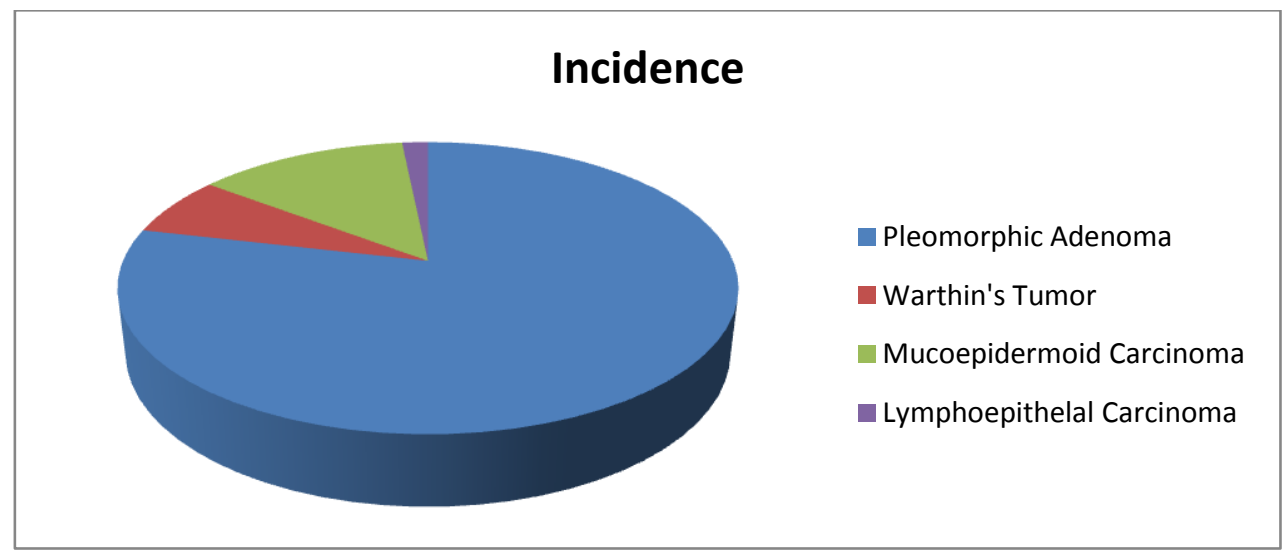

Chart No.-2 Tumour Distribution 
Of the 68 patients treated for parotid tumours, $78 \%$ of the tumours included Pleomorphic adenoma, 6.6\% included Warthin's tumour in Benign tumours and $13 \%$ included Mucoepidermoid carcinoma and $1.6 \%$ was Lymphoepithelial carcinoma.

\section{FNAC correlation with Histopathology}

Out of the 68 patients, all underwent fnac of the parotid swelling, out of which $62 \mathrm{fnac}$ reports correlated with the histopathological examination where 2 mucoepidermoid carcinomas were reported falsely as warthin's tumour and 2 cases of pleomorphorphic adenoma and 2 Mucoepidermoid carcinomas were found to be inconclusive and suspicious of Oncocytoma and Adenocystic carcinoma.

CT scan was used in patients with clinical suspicion of metastasis or positive lymph nodes noted in the neck which included 4 patients.

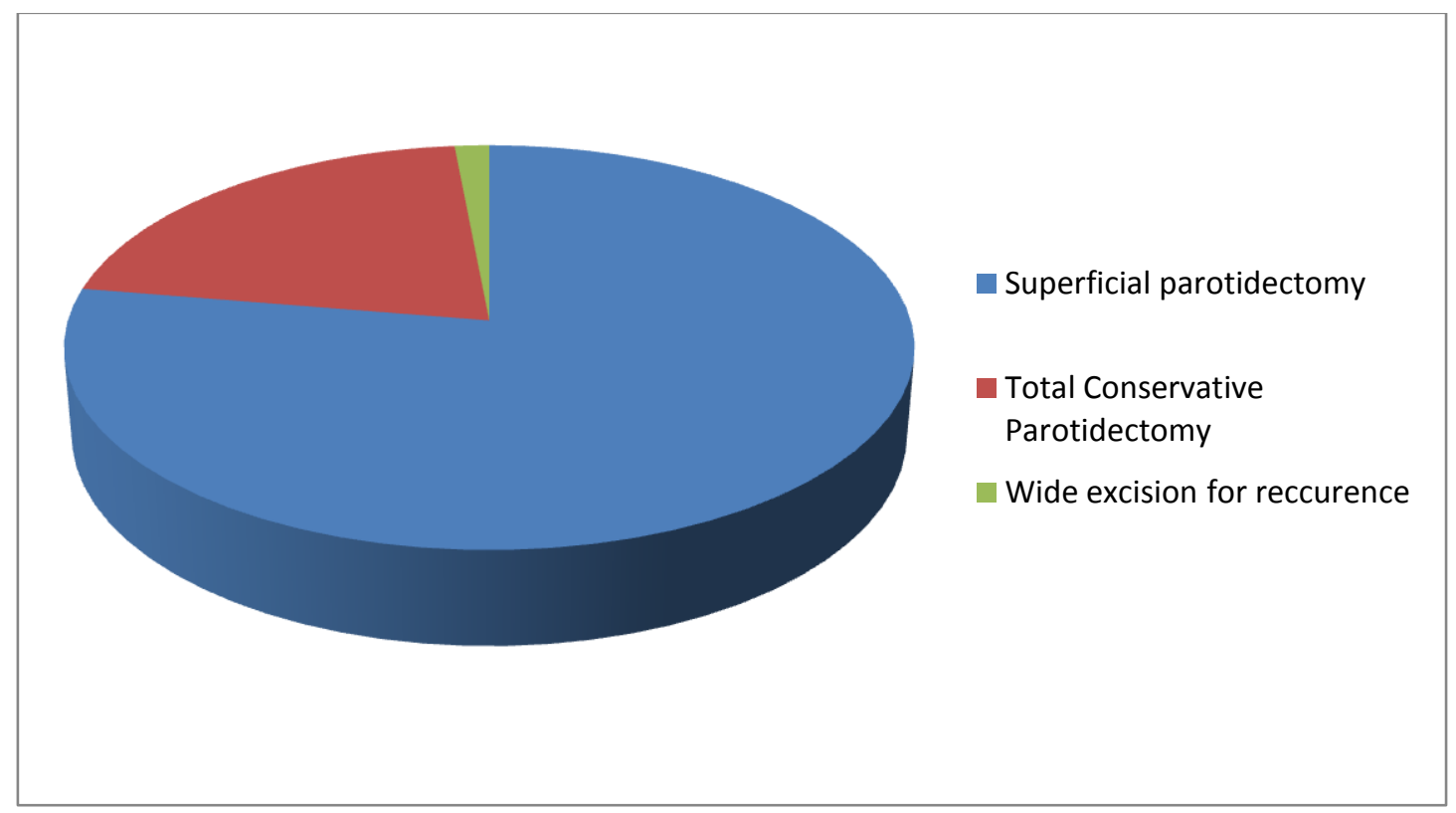

Chart No.-3 Procedure Distribution

Out of 68 patients, 52 patients underwent superficial parotidectomy (46 patients for pleomorphic adenoma, 6 patients for warthin tumour) and 14 patients underwent Total conservative parotidectomy (11 patients for parotid malignancy and 1 patients for pleomorphic adenoma recurrence and 1 patients pleomorphic adenoma involving deep lobe of parotid) and 1 underwent wide excision with neck dissection due to involvement of the hard palate post reccurence. Neck dissection also carried out in CT proven lymph node metastasis

Out of the 52 superficial parotidectomies where no neck dissection was involved, similar surgical technique used and suction/romovac drain placed insitu for closed vaccum drainage, daily post operative record of the drainage was made a note of till removal day(when drainage is of $<15 \mathrm{ml} /$ day)

\section{Complications}

Of all the patients with immediate postparotidectomy facial nerve dysfunction, $90 \%$ only experienced dysfunction in the marginal mandibular branch of the facial nerve. Eighty-nine percent of the patients achieved total recovery of facial nerve function. Only $6 \%$ of patients achieved any improvement beyond 6 months postoperatively, and all improvements occurred within 12 months postoperatively. 4 patient had permanent facial nerve palsy all these patients had $\mathrm{H}-\mathrm{B}$ grade III. Immediate postparotidectomy facial nerve dysfunction greater than $\mathrm{H}-\mathrm{B}$ grade III was the significant predictor of permanent dysfunction. 
Table 1: Different branch of facial nerve following injury

\begin{tabular}{|l|c|c|}
\hline Site & Branches & No of patients \\
\hline Single & Temporal & 0 \\
\hline & Zygomatic & 2 \\
\hline & Buccal & 3 \\
\hline & Marginal mandibular nerve & 12 \\
\hline & Cervical & 0 \\
\hline Multiple & Marginal mandibular ,buccal ,zygomatic & 3 \\
\hline All & All & 0 \\
\hline
\end{tabular}

\section{Wound seroma}

Two patients developed wound seroma in patients whom total conservative parotidectomy with lymphnode dissection done. Wound seroma is managed by repeated aspiration

\section{Skin Flap Necrosis}

Two patients developed skin flap necrosis in both groups at the distal tip of post auricular skin flap and it is treated conservatively with regular dressing and healed by secondary intention.

\section{Wound Infection}

One patient who underwent total conservative parotidectomy had wound infection .The patient is known case of diabetes mellitus and smoker. The patient is treated by drainage and antibiotics and regular dressing.

\section{Hyposthesia of Greater Auricular Nerve}

Hypoesthesia of the greater auricular nerve is a frequent consequence of parotidectomy. Patients are told that they will feel numbness around the ear, especially at the lobule. The area of numbness will improve within one year of the surgery. Ear sensation return more rapidly and more completely patients whom the posterior - branch of the great auricular nerve was preserved

Table 2: Complications

\begin{tabular}{|l|c|c|}
\hline Complications & $\begin{array}{c}\text { No of patients underwent } \\
\text { superficial parotidectomy }\end{array}$ & $\begin{array}{c}\text { No of patients underwent total } \\
\text { conservative parotidectomy }\end{array}$ \\
\hline Facial nerve paralysis & NIL & NIL \\
\hline Facial nerve paresis & $10(20.8 \%)$ & $9(90 \%)$ \\
\hline Wound seroma & 1 & 2 \\
\hline Hematoma & NIL & NIL \\
\hline Infection & NIL & 1 \\
\hline Flap necrosis & 1 & NIL \\
\hline Frey syndrome & NIL & 1 \\
\hline
\end{tabular}

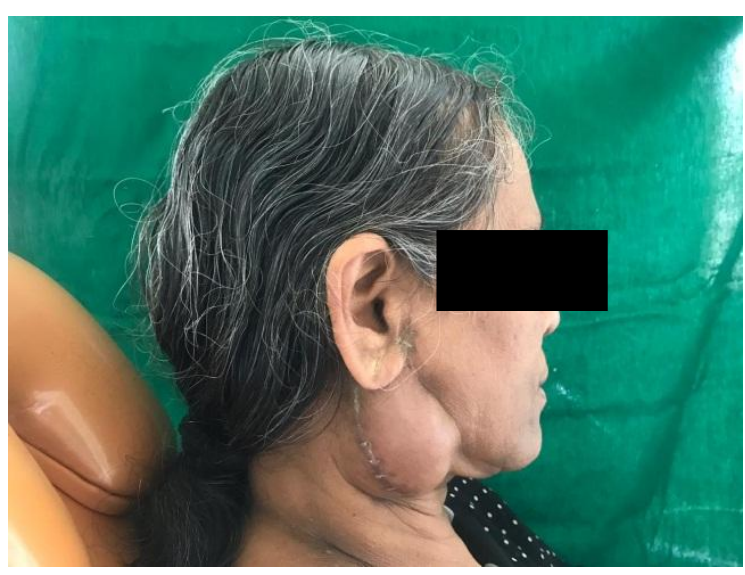

Figure 3- Seroma Formation

\section{Discussion}

This study, in congruence with other study shows that Pleomorphic adenoma is the most common benign tumour of the parotid and Mucoepidermoid carcinoma is the most common Malignant carcinoma of the Parotid.

Salivary gland tumours are rare neoplasms accounting for $2 \%-6.5 \%$ of the head- and- neck tumour $^{8}$. Parotid tumours are the most common salivary gland neoplasm. In our study of 68 patients, 39 patients are male and 29 patients are female with male to female ratio of 1.34:1 which was similar with other studies ${ }^{(11,12,13)}$. 
This study showed that Ultrasonography was the ideal screening tool and in addition to FNAC provided histological information. Usg with FNAC was found to have $90 \%$ sensitivity, $98.3 \%$ specificity, $90 \%$ positive predictive value, a $90 \%$ negative predictive value and a $90 \%$ accuracy. Higher investigations such as CT scan was only advised for palpable neck nodes or in case of suspected metastasis. ${ }^{(14)}$

In our study most of the parotid tumours are benign tumour $85 \%$ and $15 \%$ cases were malignant. Most of the tumours are located in the superficial lobe of the parotid gland, where benign tumours are more common, while deep lobe can be equally affected by both benign and malignant tumours. In our study, 95\% cases were involved the superficial lobe and 5\% cases were deep lobe tumour(one pleomorphic adenoma and 2 mucoepidermoid carcinoma)which corresponding with other Study ${ }^{(15,16)}$.

Facial nerve palsy is the most common postoperative complication encountered following parotid surgery. Mechanical trauma, such as nerve compression, crushing, and stretching, and electrocoagulation heat damage are possible etiologies. Nerve stretching is the most probable cause. ${ }^{(17)}$

Some studies have demonstrated that nerve elongation of $6 \%$ because of stress-strain can cause perineurium tears and result in loss of the compound action potential $^{(17)}$.

In our study, superficial parotidectomy was performed in 52 cases. Among this facial nerve paresis was noted in 10 cases (20.8\%) Total conservative parotidectomy was performed in 14 cases. Among these facial nerve paresis was noted in 10 cases $(83.3 \%)$. Hyposthesia of greater auricular nerve is seen in 7 cases $(14.5 \%)$ of superficial parotidectomy and 9 cases $(75 \%)$ of total conservative parotidectomy .So, in this study shows that, facial nerve paresis is more common in total conservative parotidectomy $(83.3 \%)$ than superficial parotidectomy $(20.8 \%)$. This result is similar to a another study ${ }^{(18)}$. The branch of the facial nerve most at risk for injury during parotidectomy is marginal mandibular nerve. In this study $60 \%$ cases marginal mandibular nerve is involved. All cases of facial nerve paresis improved after $48 \mathrm{hrs}$ and resolved within 2 months.

Facial paresis was found to be the most common adversity followed by wound seroma. These complications were also noticed to be more in case of total parotidectomy compared to superficial parotidectomy.

\section{Conclusion}

The incidence of parotid salivary gland tumours has seen an increasing trend in younger age group possibly due to changing lifestyle and dietary habits. Ultrasonography with FNAC was found to be both sensitive and specific in diagnosing parotid tumours with added CT surveillance needed for added neck and lymph node involvement. Parotidectomy is the main modality of treatment. The type of parotidectomy is planned based on the intraglandular location of the tumour. The best means of reducing iatrogenic facial nerve injury, in parotid surgery, still remains a clear understanding of the anatomy, good surgical technique with the use of multiple anatomic landmarks. The goals of rational and risk of operation such as general complication, cosmetic sequalae of the incision to be explained beforehand. All patients to be explained of chance of temporary or permanent facial paresis. If the complication arises surgeon should be able to manage and reassure the patient. However, Parotidectomy continues to be a challenge on account of the wide range of tumours encountered and the variations in size and location. It is, therefore, mandatory that this operation be performed by experienced and skilled surgeons to prevent complication and manage complication if arises.

\section{References}

1. Chauhan, N., Shah, J.A. Parotid Gland Tumours: Our Experience. Indian J 
Otolaryngol Head Neck Surg 71, 378-382 (2019)

2. Bittar RF, Ferraro HP, Ribas MH, Lehn CN. Facial paralysis after superficial parotidectomy: analysis of possible predictors of this complication. Braz $J$ Otorhinolaryngol. 2016;82(4):447-451. doi:10.1016/j.bjorl.2015.08.024

3. Maahs GS, OppermannPde O, Maahs LG, Machado Filho G, Ronchi AD. Parotid gland tumors: a retrospective study of 154 patients. Braz $J \quad$ Otorhinolaryngol. 2015;81(3):301-306.

doi:10.1016/j.bjorl.2015.03.007

4. Olsen KD. Superficial parotidectomy. OperTechn Gen Surg 2004;6:102-14.

5. Henney SE, Brown R, Phillips D. Parotidectomy: the timing of postoperative complications. Eur Arch Otorhinolaryngol 2010;267:131-5.

6. Gaillard C, Périé S, Susini B, St Guily JL. Facial nerve dysfunction after parotidectomy: the role of local factors Laryngoscope. 2005;115:287-291. doi: 10.1097/01.mlg.0000154735.61775.cd. [P ubMed] [CrossRef] [Google Scholar]

7. Nichols RD, Stine PH, Bartschi LR. Facial nerve function in 100 consecutive parotidectomies. Laryngoscope. 1979;89:1 930-1934. doi: 10.1288/00005537197912000-00005. [PubMed] [CrossRef] [Google Scholar]

8. Mehle ME, Kraus DH, Wood BG, Benninger MS, Eliachar I, Levine HL, Tucker HM, Lavertu P. Facial nerve morbidity following parotid surgery for benign disease: the Cleveland Clinic Foundation experience. Laryngoscope. 1993; 103:386-388. doi: 10.1002/lary.5541030404. [PubMed] [CrossRef] [Google Scholar]

9. Roh LJ, Park CI. A prospective, randomized trial for use of prednisolone in patients with facial nerve paralysis after parotidectomy. Am J Surg 2008; 196:746750 .

10. Wormald R, Donnelly M, Timon C. 'Minor' morbidity after parotid surgery via the modified Blair incision. $J$ Plast Reconstr Aesthet Surg 2008; 62:10081011.

11. Lin $\mathrm{CC}$, Tsai $\mathrm{MH}$, Huang $\mathrm{CC}$, Hua $\mathrm{CH}$, Tseng HC, Huang ST. Parotid tumors: A 10-year experience. Am J Otolaryngol Head Neck Med Surg 2008;29:94-100.

12. Edward J. Dunn, Tyler Kent, James Hines, Isidore Cohn. Parotid Neoplasms: A Report of 250 Cases and Review of the Literature. Ann.Surg 1976;184:500-5.

13. Potdar GG. Mucoepidermoid tumors of salivary glands in Western India. Arch Surg 1968;97:657-61.

14. Gudmundsson JK, Ajan A, Abtahi J. The accuracy of fine-needle aspiration cytology for diagnosis of parotid gland masses: a clinicopathological study of 114 patients. $J$ Appl Oral Sci. 2016;24(6):561-567. doi:10.1590/1678-775720160214

15. Glesson M, Cowson R. Benign salivary gland tumour, In: Scoot-Brown's Otolaryngology Head and Neck Surgery, Hodder Arnold, London, 2008; 2475-2491.

16. John C, Watkinson, Masur and Gazi, Jonet W. Wilson. Tumour of major salivary gland, Steel and Marians, $4^{\text {th }}$ edition, 2000; 441-581

17. Grewal R, Xu J, Sotereanos DG, Woo SL. Biomechanical properties of peripheral nerves. Hand Clin 1996;12:195-204.

18. Marchese-Ragona R, De Filippis C, Marioni G, Staffieri A. Treatment of complications of parotid gland surgery. Acta Otorhinolaryngol Ital. 2005; 25(3):174-8. 